\title{
Is Earth-based scaling a valid procedure for calculating heat
}

\section{flows for Mars?}

Javier Ruiz $^{\mathrm{a}, *}$, Jean-Pierre Williams ${ }^{\mathrm{b}}$, James M. Dohm ${ }^{\mathrm{c}}$, Carlos Fernández ${ }^{\mathrm{d}}$, Valle López ${ }^{\mathrm{e}}$

${ }^{a}$ Departamento de Geodinámica, Facultad de Ciencias Geológicas, Universidad Complutense de Madrid, 28040 Madrid, Spain

${ }^{\mathrm{b}}$ Department of Earth and Space Sciences, University of California, Los Angeles, CA 90095, USA

${ }^{c}$ Earth-Life Science Institute, Tokyo Institute of Technology, Meguro, Tokyo 152-8551, Japan

${ }^{\text {d }}$ Departamento de Geodinámica y Paleontología, Universidad de Huelva, Campus de El Carmen, 21071 Huelva, Spain

e Escuela Técnica Superior de Ingenieros en Topografía, Geodesia y Cartografía, Universidad Politécnica de Madrid, Carretera de Valencia, km 7.5, 28031 Madrid, Spain

* Corresponding author. E-mail: jaruiz@ucm.es (J. Ruiz) 
Editorial correspondence to:

Javier Ruiz

Departamento de Geodinámica,

Facultad de Ciencias Geológicas,

Universidad Complutense de Madrid,

28040 Madrid, Spain

E-mail: jaruiz@ucm.es 


\begin{abstract}
Heat flow is a very important parameter for constraining the thermal evolution of a planetary body. Several procedures for calculating heat flows for Mars from geophysical or geological proxies have been used, which are valid for the time when the structures used as indicators were formed. The more common procedures are based on estimates of lithospheric strength (the effective elastic thickness of the lithosphere or the depth to the brittle-ductile transition). On the other hand, several works by Kargel and co-workers have estimated martian heat flows from scaling the present-day terrestrial heat flow to Mars, but the so-obtained values are much higher than those deduced from lithospheric strength. In order to explain the discrepancy, a recent paper by Rodriguez et al. (Rodriguez, J.A.P., Kargel, J.S., Tanaka, K.L., Crown, D.A., Berman, D.C., Fairén, A.G. Baker, V.R., Furfaro, R., Candelaria, P., Sasaki, S., [2011]. Icarus 213, 150-194) criticized the heat flow calculations for ancient Mars presented by Ruiz et al. (Ruiz, J., Williams, J.-P., Dohm, J.M., Fernández, C., López, V., [2009]. Icarus 207, 631-637) and other studies calculating ancient martian heat flows from lithospheric strength estimates, and casted doubts on the validity of the results obtained by these works. Here however we demonstrate that the discrepancy is due to computational and conceptual errors made by Kargel and co-workers, and we conclude that the scaling from terrestrial heat flow values is not a valid procedure for estimating reliable heat flows for Mars.
\end{abstract}

Key words: Mars; Mars, interior; Tectonics; Thermal histories.

\title{
1. Introduction
}

Numerous studies have attempted to calculate paleo heat flows for several regions 
and times of Mars through a diversity of approximations. The most commonly used procedure (e.g., Solomon and Head, 1990; McGovern et al., 2004; Grott et al., 2005; Ruiz et al., 2006a,b, 2011; Kronberg et al., 2007; Grott and Wieczorek, 2012) is the conversion of estimates of the effective elastic thickness of the lithosphere (usually denoted as $T_{e}$ ) to heat flows by comparing with an equivalent strength envelope, which depends on the temperature profile. Another methodology consists of deducing the heat flow from the depth to the brittle-ductile transition (BDT) associate with large thrust faults (Schultz and Watters, 2001; Grott et al., 2007; Ruiz et al., 2008, 2009). Both kinds of calculations are, therefore, based on estimates of lithospheric strength. Alternatively, some works have modeled the heat flow necessary to cause melting in chaotic areas (Schumacher and Zegers, 2011), relaxation of crater topography (Karimi et al., 2012), or even the heat flow consistent with melting pressures and degrees of partial melting proposed from the estimated geochemistries of volcanic provinces (Batatoux et al., 2011). These paleo heat flow estimations were derived by using different sets of parameters, and comparisons are not always easy, but the obtained values are usually comparable, at least when the effect of different assumptions are taken into account.

Thermal history models also provide calculations of the average surface heat flow of Mars as a function of time (e.g., Hauck et al., 2002; Grott and Breuer, 2010). In general, thermal history models predict surface heat flows somewhat higher than those obtained from geophysical or geological proxies (which could have implications on our knowledge of the thermal evolution of Mars; see Ruiz et al., 2011), but the estimated values are comparable to those derived from lithospheric strength.

On the other hand, several works by Kargel and co-workers (Kargel, 2004; Kargel 
et al., 2006; Rodriguez et al., 2011; hereafter collectively referred as Kargel and coworkers) have used heat flows of 30 and $120 \mathrm{~mW} \mathrm{~m}^{-2}$, respectively, for the present-day and for $2.6 \mathrm{Ga}$ (the latter is considered by these authors to be representative of the Late Hesperian or Early Amazonian epochs). These heat flow values are based on scaling the present-day terrestrial heat flow to Mars, and are much higher than those obtained from both geophysical/geological proxies and thermal history models. Indeed, lithospheric strength-based calculations usually obtain heat flows of at most $20 \mathrm{~mW} \mathrm{~m}^{-2}$ and $30-40 \mathrm{~mW}$ $\mathrm{m}^{-2}$, respectively, for present-day and Late Hesperian/Early Amazonian times (McGovern et al., 2004; Ruiz et al., 2011).

In relation to this discrepancy (mostly with works based on the BDT depth), Rodriguez et al. (2011) wrote (see their page 147): "From a cosmochemical viewpoint, we doubt that heat flow could be as low as the 'tectonic' based estimates, as they would imply a composition that is highly depleted, relative to Earth, in both refractory lithophile (U and Th) and volatile-lithophile elements $(\mathrm{K})$; this combination and the inferred degree of depletion generally does not occur for silicate bodies in the Solar System, and it points out a fundamental error in the reasoning based on the tectonic estimates." More specifically, Rodriguez et al. (2011) consider the heat flow results in Ruiz et al. (2009) to be low, and they claim that it is a consequence of assuming low potassium, thorium, and uranium abundances for Mars. These authors also claim that Ruiz et al. (2006b, 2008, 2009) did not take into account the release of heat stored in Mars from past radioactive heat generation and global differentiation.

Heat flow is an important parameter in the understanding of the thermal evolution of a planetary body, and specifically for Mars. For that reason, we consider it necessary to 
clarify the point of the discrepancy between the values obtained from geophysical/geological proxies and those proposed by Kargel and co-workers. In this work, we therefore assess: 1) the criticism of Rodiguez et al. (2011) to the calculation of heat flows from lithospheric strength (and specifically those performed by Ruiz et al. (2006, 2008, 2009), hereafter collectively referred to as Ruiz and co-workers); 2) the derivation of the heat flow values proposed by Kargel and co-workers; and 3) the general validity of scaling Earth's heat flows for the calculation of average martian heat flows for a given time.

We show that the criticisms of Rodriguez et al. (2011) are invalid, that the scaled heat flow of $120 \mathrm{~mW} \mathrm{~m}^{-2}$ proposed by Kargel and co-workers for $2.6 \mathrm{Ga}$ is an erroneous value, and that the scaling from terrestrial values is not a valid procedure to estimate heat flows for Mars. Thus, the discrepancy noted by Rodiguez et al. (2011) is a consequence of computational and conceptual errors made by Kargel and co-workers.

\section{The role of heat-producing elements abundances in the calculation of heat flows from lithosphere strength}

Recently Rodriguez et al. (2011) noted a strong discrepancy between heat flows calculated from lithospheric strength (referred by these authors as tectonic-based estimates) and the values derived by Kargel and co-workers. These authors consider that lithospheric strength-based heat flow calculations for Mars imply a highly depleted composition in U, Th, and K relative to Earth, which would indicate a fundamental error in the lithospheric strength-based heat flow estimates.

More specifically, Rodriguez et al. (2011) consider that the heat flow calculations 
presented in Ruiz et al. (2009) used low potassium, thorium and uranium abundances for Mars. For example, by using the crustal potassium mean abundance referred in Ruiz et al. (2009), which is 3300 ppm (value coming from Taylor et al. (2006)), and a crustal density and thickness of $2900 \mathrm{~kg} \mathrm{~m}^{-3}$ and $80 \mathrm{~km}$ respectively, Rodriguez et al. (2011) obtain potassium abundances less than 172 ppm for bulk Mars, a value lower than their prevision based on assuming the same abundances as for the average Earth, and they indicate that similar results are obtained for thorium and uranium. These authors also wrote (p. 147): "For their [Ruiz et al. (2009)] preferred model where the radiogenic elements are mainly concentrated at those abundances in the upper quarter of the crust, and the mantle supplies a roughly similar or slightly less abundant of heat, the inferred bulk-Mars abundances of heat-producing elements is even far less, with greater depletions of $\mathrm{K}, \mathrm{U}$, and Th than indicated above.” Moreover, Rodriguez et al. (2011) also claim that Ruiz et al. (2006b, 2008, 2009) did not take into account the release of heat stored in Mars from past radioactive heat generation and global differentiation.

However, the criticisms of Rodriguez et al. (2011) arise from a misunderstanding of the work of Ruiz and co-workers. For example, the paper by Ruiz et al. (2009) performed an upper limit calculation of the surface heat flow at the Warrego rise (valid for the time when the thrust faults were formed: the Noachian Period and not the Hesperian) by assuming heat-producing elements (HPE) homogeneously distributed in the crust. This paper showed that, for the Warrego rise, a crust with homogeneously distributed HPE is not consistent with the local BDT depth, and therefore a stratified crust is favored for this region, but does not propose any particular preferred model, and there is no mention to a model with the HPE concentrated in the upper quarter of the crust. Thus, Rodriguez et al. 
(2011) are errant in attributing this preference to the work by Ruiz et al. (2009).

The work by Ruiz et al. (2009) used HPE abundances derived from Mars Odyssey Gamma Ray Spectrometer (GRS) measurement (Taylor et al., 2006); we realize that such estimates may be improved with future missions and/or studies. The actual HPE abundances would be somewhat increased by renormalizing considering the volatile content in order to obtain a composition more representative of crustal rocks and not surface contamination (Hahn et al., 2011), but this increase, about ten percent, does not alter the conclusions of Ruiz et al. (2009). Ruiz et al. (2009) performed a regional study, and the high crustal thicknesses in the Warrego rise are not representative for martian averages. Furthermore, we do not assume that all the HPE (including potassium) are in the crust, and our approach is independent of HPE abundances in the mantle. Thus, the calculation by Rodriguez et al. of potassium abundances in bulk Mars from "our" assumptions is not valid.

In the calculations by Ruiz et al. (2006b, 2008, 2009) a contribution to the surface heat flow is due to radioactive heating in the crust whereas the remainder reaches the crust from the mantle, but there is no assumption on the origin(s) of the mantle heat, and it could certainly include "fossil heat": the criticism of Rodriguez et al. related to the lack of use of stored heat flow is simply not applicable. Moreover, Ruiz et al. (2009) used their results for surface heat flow, along with the condition of non-negative heat flow (or of mantle heat flow being a given fraction of the surface heat flow), in order to obtain upper limits to the thickness of a homogeneous crust (which were compared with crustal thickness models for Warrego rise), but no calculation of mantle heat flow was presented.

Thus, it is clear that the discrepancy between the heat flow derived by Kargel and 
co-workers and those obtained from lithospheric strength are not related to assumptions on HPE abundances in the latter. In the next section, we therefore re-evaluate the estimation of martian heat flows proposed by Kargel and co-workers.

\section{Scaling of radioactive heat generation and heat flows from present-day Earth to ancient Mars}

The heat flows proposed for Mars by Kargel and co-workers were explicitly "massand surface area-scaled from Earth's modern global mean heat flow" (Rodriguez et al., 2011, p. 174), based on the assumption of a similar concentration of HPE elements in both planets. This scaling implies an "effective" heat loss rate per mass unit (which we denote as $H$ ) equal for Mars and Earth. Under this condition, the surface heat flow in each planet is given by $H M /\left(4 \pi R^{2}\right)$, where $M$ and $R$ are, respectively, mass and mean radius of the planet. Thus, the ratio between martian and terrestrial heat flow should be given by

$$
\frac{F_{M}}{F_{E}}=\frac{M_{M} R_{E}^{2}}{M_{E} R_{M}^{2}}
$$

Using standard values for the respective parameters $\left(M_{E}=5.9736 \times 10^{24} \mathrm{~kg}, R_{E}=6371 \mathrm{~km}\right.$, $M_{M}=6.4185 \times 10^{23} \mathrm{~kg}$, and $\left.R_{M}=3390 \mathrm{~km}\right)$,

$$
F_{M} \approx 0.38 F_{E},
$$

Taking $F_{E}=87 \mathrm{~mW} \mathrm{~m}^{-2}$ (Pollack et al., 1993; for a review on the terrestrial heat flow see 
Jaupart and Mareschal, 2011), $F_{M} \approx 33 \mathrm{~mW} \mathrm{~m}^{-2}$ is obtained, which is similar to the value of $30 \mathrm{~mW} \mathrm{~m}^{-2}$ derived by Kargel (2004) for present-day Mars. Kargel (2004, p. 376) stated that "radiogenic heating in recent eons is declining by about a factor of 2 every 1.3 billions years", and on this basis Kargel et al. (2006) and Rodriguez et al. (2011) propose a heat flow for 2.6 Ga (age roughly corresponding to Late Hesperian or Early Amazonian times after these authors) of $120 \mathrm{~mW} \mathrm{~m}^{-2}$, four times their scaled present-day value.

Even accepting the basic assumptions of Kargel and co-workers, the extrapolation to the past of Mars from the "scaled present-day heat flow" is, however, erroneous. Figure 1 shows the relative (with respect to the present-day value) radioactive heat production due to potassium, thorium and uranium (including ${ }^{238} \mathrm{U}$ and ${ }^{235} \mathrm{U}$ ) as a function of age, calculated from standard decay constants (e.g., Van Schmus, 1995). Heat production variations are higher for potassium, and very low for thorium. By comparison, the point corresponding to four times the present-day value is also shown for $2.6 \mathrm{Ga}$, since this value was used by Kargel and co-workers to represent the relative total heat production in that time. Figure 2 shows the relative radioactive heat production, with respect to the present-day value, due to bulk Earth HPE abundances, taken from Kargel and Lewis (1993) for consistency with Rodriguez et al. (2011): $\mathrm{K}=225 \mathrm{ppm}$, $\mathrm{Th}=54.3 \mathrm{ppb}$, and $\mathrm{U}=15.2 \mathrm{ppb}$. Figure 2 also shows the point corresponding to four times the present-day value for $2.6 \mathrm{Ga}$, as used by Kargel and co-workers.

It is clear that the radioactive heat production obtained by using the bulk Earth HPE abundances of Kargel and Lewis (1993) does not vary by a factor four in $2.6 \mathrm{Ga}$, as required by Kargel and co-workers in order to obtain a "scaled martian heat flow" of 120 $\mathrm{mW} \mathrm{m}^{-2}$ in that specific time. The temporal scaling of Kargel et al. (2006) and Rodriguez et 
al. (2011) is therefore simply invalid. In fact, Figure 2 shows that the radioactive heat production for the above HPE abundances and 2.6 Ga should be around 2.1 times the present-day value (on the other hand, the relative radioactive heat production four times the present-day value proposed by Kargel and co-workers for $2.6 \mathrm{Ga}$ is very close to the relative heat production due to potassium in that time). Thus, if the temporal scaling of Kargel and co-workers is accepted, then it should give a surface heat flow around $60 \mathrm{~mW}$ $\mathrm{m}^{-2}$ for $2.6 \mathrm{Ga}$, half of the value assigned by Kargel et al. (2006) and Rodriguez et al. (2011). Similar conclusions on the temporal variation of radioactive heat production are obtained if we use HPE bulk abundances for Mars based on other compositional models (Figure 2 also represents the relative radioactive heat production predicted by the model of Wänke and Dreibus (1988)).

In this section we have shown that the temporal scaling of Kargel and co-workers (and specifically that of Kargel et al. (2006) and Rodriguez et al. (2011)) is erroneous by a factor two, which makes the differences with heat flow calculations based on lithospheric strength much less pronounced. However, there persists a roughly factor-two discrepancy, which requires additional explanation.

\section{A major role, or not, for hydrothermal circulation}

Rodriguez et al. (2011) have argued that cooling of mid crustal levels by hydrothermal circulation could reconcile their high heat flow values with estimates of the BDT depth obtained by several authors. So, the actual temperature gradient would be higher than a purely conductive one. In this sense, Parmentier and Zuber (2007) have proposed that a substantial amount of heat could be transported by hydrothermal cooling of 
the upper crust.

The argument of Rodriguez et al. (2011) could be potentially valid only for heat flows calculated from the depth of thrust faults, because in this case the calculation depends on the temperature profile between the surface and the BDT depth. Otherwise, this argument cannot be applied to heat flows calculated from the effective elastic thickness of the lithosphere. Indeed, hydrothermal circulation could only operate above the brittleductile transition, below which porosity is largely eliminated by viscous creep (Hanna and Phillips, 2005; Dempsey et al., 2012): heat flows calculated from the effective elastic thickness are based on the temperature-dependence of ductile strength, and hence on the conductive temperature profile in the ductile layer(s) of the lithosphere, but insensitive to the temperature profile in the brittle crust (see also Ruiz et al., 2011). This implies that, for a given temperature at the BDT, the temperature profile below the BDT depth obtained from $T_{e}$ would be the same if hydrothermal circulation is acting in the upper crust or not. From this we conclude that, for heat flows calculated from $\left.T_{e}: 1\right)$ the obtained sublithospheric heat flow is not changed, and 2) any increase of the surface heat flow (in excess of the radioactive contribution) with respect to that in the BDT must come from cooling the crust above the BDT, which could work locally, but it does not seem reasonable to expect a large-scale influence on heat flow in this way (Ruiz et al., 2011). Since DBT depth- and $T_{e}$-based heat flows are comparable, the discrepancy between the heat flow proposed by Kargel and co-workers and those derived from lithospheric strength cannot be explained by hydrothermal circulation of heat. 


\section{The scaling reasoning}

Even after correcting the factor-two error in temporal scaling of Kargel and coworkers, it is clear then that a substantial discrepancy remains between heat flows obtained from lithospheric strength and those derived from planetary scaling. Moreover, this discrepancy is not easily explained, as shown in the previous section, through vigorous hydrothermal cooling in the crust above the brittle-ductile transition. Alternatively, the cause of discrepancy could be related to a general non-validity of the scaling reasoning.

Rodriguez et al. (2011) indicates that their heat flow calculations also assumed a component of stored heat released (i.e., secular cooling), similarly to Earth. Thus, scaling the average present-day terrestrial surface heat flow to ancient Mars implies in fact assuming that the proportion between the total radioactive heat production and the total heat loss (usually known as the Urey ratio) must be, at least roughly, the same in both planets during a substantial fraction of the planetary history. However, it is well established that differences in convective regime (e.g., plate tectonics vs. stagnant lid convection) produce different surface heat flow values (for a review see Schubert et al., 2001). The thermal histories of Earth and Mars have been very different: although some authors have suggested that Mars experienced an ancient phase of plate tectonics (e.g., Sleep, 1994; Baker et al., 2007), this phase would be, at most, limited to the earliest part of the martian history (e.g., Frey, 2006). During the last $4 \mathrm{Ga}$ or so this planet has been in the stagnant lid regime, which makes the assumption of a similar proportion between radioactive heat production and total heat loss for Earth and Mars arbitrary, and therefore invalidates the procedure of scaling terrestrial heat flows to Mars. Even for stagnant-lid convection, differences in convective vigor produce different heat flows (for an analysis of present-day 
stagnant-lid convection on Mars see Li and Kiefer (2007)), reinforcing our conclusions. Also, changes in convective regime or efficiency could have occurred in the Earth's history (e.g., Korenaga, 2003; Silver and Behn, 2008), and so, the implicit assumption of similar time-averaged proportion between radioactive heat production and total heat loss for Earth and Mars does not have therefore any solid basis. Finally, several lines of argumentation suggest than the contribution of secular cooling to the current heat flow is lower for Mars than in Earth (e.g., Ruiz et al., 2011; Grott et al., 2013).

Rodriguez et al. (2011) also stated that the calculation of martian heat flow from the Earth's global composition of Kargel and Lewis (1993), HPE decay constants, and a time of 2.6 Ga give similar results to those obtained by Kargel and co-workers through the scaling procedure. However, the heat flows proposed by Kargel and co-workers for Mars (including the value for $2.6 \mathrm{Ga}$ as corrected in Section 3) greatly exceed the heat flows equivalent to the total heat production that can be justified by the HPE bulk abundances supposedly assumed by these authors (Figure 3).

\section{Conclusions}

In the previous sections we demonstrated that:

1) The criticism by Rodriguez et al. (2011) of the works by Ruiz et al. (2006, 2008, 2009) is erroneous and groundless, since it attributes to the cited papers assumptions that are inexistent in these papers.

2) Kargel and co-workers overestimate by approximately a factor of two the radioactive heat production for $2.6 \mathrm{Ga}$ (time chosen as representative by these authors for Late Hesperian or Early Amazonian times), which artificially enlarge the discrepancy 
between their heat flow estimates and those derived from lithospheric strength estimates.

3) The scaling procedure for calculated heat flows for Mars used by Kargel and coworkers is not supported by any solid rationale, since plate tectonics and stagnant lid convection transfer the internal heat very differently; and temporal changes in convective regime or efficiency could have occurred in the Earth's history.

In summary, we have demonstrated that the discrepancy between the heat flows proposed by Kargel and co-workers and those based on lithospheric strength estimates are not due to any fundamental error in the works using the lithospheric strength approach, but to computational and conceptual errors made by Kargel and co-workers. Thus, we conclude that the scaling from terrestrial heat flow values is not a valid procedure for estimating reliable heat flows for Mars. Currently, in the absence of direct measurements of presentday values, the primary technique for calculating martian heat flows is the analysis of lithospheric strength, although other possibilities recently suggested, as melting in chaotic areas, relaxation of crater topography, or estimates of melting pressures and temperatures of magmas, are also of interest as independent indicators.

\section{Acknowledgements}

We thank the comments from two anonymous reviewers. JR work was supported by a contract Ramón y Cajal co-financed from the Ministerio de Economía y Competitividad of Spain and the European Social Fund (ESF). 


\section{References}

Baker, V.R., Maruyama, S., Dohm, J.M., 2007. Tharsis superplume and the geological evolution of early Mars. In: Yuen, D.A., Maruyama, S., Karato, S.-I., Windley, B.F. (Eds.), Superplumes: beyond plate tectonics. Springer, Berlin, pp. 507-523.

Baratoux, D., Toplis, M.J., Monnereau, M., Gasnault, O., 2011a. Thermal history of Mars inferred from orbital geochemistry of volcanic provinces. Nature 472, 338-341 [corrected: Nature 475, 254].

Dempsey, D.E., Rowland, J.V., Zyvoloski, G.A., Archer, R.A., 2012. Modeling the effects of silica deposition and fault rupture on natural geothermal systems. J. Geophys. Res. 117, B05207, doi:10.1029/2012JB009218.

Frey, H.V., 2006. Impact constraints on, and a chronology for, major events in early Mars history. J. Geophys. Res. 111, E08S91, doi:10.1029/2005JE002449.

Grott, M., Breuer, D., 2010. On the spatial variability of the martian elastic lithosphere thickness: evidence for mantle plumes? J. Geophys. Res. 115, E03005, doi:10.1029/2009JE003456.

Grott, M., Wieczorek, M.A., 2012. Density and Lithospheric Structure at Tyrrhena Patera, Mars, from Gravity and Topography Data. Icarus, http://dx.doi.org/10.1016/j.icarus.2012.07.008.

Grott, M., Hauber, E., Werner, S.C., Kronberg, P., Neukum, G., 2005. High heat flux on ancient Mars: Evidence from rift flank uplift at Coracis Fossae. Geophys. Res. Lett. 32, L21201, doi:10.1029/2005GL023894.

Grott, M., E. Hauber, S.C. Werner, P. Kronberg, G. Neukum, 2007. Mechanical modelling of thrust faults in the Thaumasia region, Mars, and implications for the Noachian heat 
flux. Icarus 186, 517-526.

Grott, M., et al., 2013. Long-term evolution of the martian crust-mantle system. Space Sci. Rev. 174, 49-111.

Hahn, B.C., McLennan, S.M., Klein, E.C., 2011. Martian Surface Heat Production and Crustal Heat Flow from Mars Odyssey Gamma-Ray Spectrometry Geophys. Res. Lett. 38, L14203, doi:10.1029/2011GL047435.

Hanna, J.C., Phillips, R.J., 2005. Hydrological modeling of the Martian crust with application to the pressurization of aquifers. J. Geophys. Res. 110, E01004, doi:10.1029/2004JE002330.

Hauck, S.A., Phillips, R.J., 2002. Thermal and crustal evolution of Mars. J. Geophys. Res. 107, 5052, doi:10.1029/2001JE001801.

Jaupart, C., Mareschal, J.-C., 2011. Heat generation and transport in the Earth. Cambridge Univ. Press, Cambridge, 464 pp.

Kargel, J.S., 2004. Mars: a warmer, wetter planet. Springer, New York, 557 pp.

Kargel, J.S., Lewis, J.S., 1993. The composition and early evolution of Earth. Icarus 105, 125.

Kargel et al., 2006. Martian hydrogeology sustained by thermally insulating gas and salt hydrates. Geology 35, 975-978.

Karimi, M., Dombard A.J., Williams, R.M., 2012. A study of the thermal evolution of Mars via viscoelastic relaxation of large craters. In: Proc. Lunar Planet. Sci. Conf. 43th. Abstract 2712

Korenaga, J., 2003. Energetics of mantle convection and the fate of fósil heat. Geophys. Res. Lett 30, 1437, doi: 10.1029/2003GL016982. 
Kronberg, P., et al., 2007. Acheron Fossae, Mars: Tectonic rifting, volcanism, and implications for lithospheric thickness. J. Geophys. Res. 112, E04005, doi:10.1029/2006JE002780.

Li, Q., Kiefer, W.S., 2007. Mantle convection and magma production on present-day Mars: effects of temperature-dependent rheology. Geophys. Res. Lett. 34, L16203 doi:10.1029/2007GL030544.

McGovern, P.J., et al., 2004. Correction to Localized gravity/topography admittance and correlation spectra on Mars: Implications for regional and global evolution. J. Geophys. Res. 109, E07007, doi:10.1029/2004JE002286.

Parmentier, E.M., Zuber, M.T., 2007. Early evolution of Mars with mantle compositional stratification or hydrothermal crustal cooling. J. Geophys. Res. 112, E02007, doi:10.1029/2005JE002626.

Pollack, H.N., Hunter, S.J., Johnson, J.R., 1993. Heat flow from the Earth interior: analysis of the global data set. Rev. Geophys. 31, 267-280.

Rodriguez, J.A.P., et al., 2011. Secondary chaotic terrain formation in the higher outflow channels of southern circum-Chryse, Mars. Icarus 213, 150-194.

Ruiz, J., McGovern, P.J., Tejero, R., 2006a. The early thermal and magnetic state of the cratered highlands of Mars. Earth Planet. Sci. Lett. 241, 2-10.

Ruiz, J., Tejero, R., McGovern, P.J., 2006b. Evidence for a differentiated crust at Solis Planum, Mars, from lithospheric strength and heat flow. Icarus 180, 308-313.

Ruiz, J., et al., 2008. Ancient heat flow, crustal thickness, and lithospheric mantle rheology in the Amenthes region, Mars. Earth Planet. Sci. Lett. 270, 1-12.

Ruiz, J., Williams, J.P., J.M., Fernández, C., López, V., 2009. Ancient heat flows and 
crustal thickness at Warrego rise, Thaumasia Highlands, Mars: Implications for a stratified crust, Icarus 207, 631-637, 2010.

Ruiz, J., McGovern, P.J., Jiménez-Díaz, A., López, V., Williams, J.P., Hahn, B.C. Tejero, R., 2011. The thermal evolution of Mars as constrained by paleo-heat flows, Icarus $215,508-517$.

Schubert, G., Turcotte, D.L., Olson, P., 2001. Mantle convection in the Earth and Planets. Cambridge University Press, Cambridge, 940 pp.

Schultz, R.A., Watters, T.R., 2001. Forward mechanical modeling of the Amenthes Rupes thrust fault on Mars. Geophys. Res. Lett. 28, 4659-4662.

Schumacher, S., Zegers, T.E., 2011. Aram Chaos and its constraints on the surface heat flux of Mars. Icarus 2011, 305-315.

Silver, P.G., Behn, M.D., 2008. Intermittent plate tectonics? Science 319, 85-88.

Sleep, N.H., 1994. Martian plate tectonics. J. Geophys. Res. 99, 5639-5655.

Solomon, S.C., Head, J.W., 1990. Heterogeneities in the thickness of the elastic lithosphere of Mars: Constraints on heat flow and internal dynamics. J. Geophys. Res. 95, 11,073-11,083.

Taylor, G.J., et al., 2006. Bulk composition and early differentiation of Mars. J. Geophys. Res. 111, E03S10, doi:10.1029/2005JE002645. [Printed 112(E3), 2007]

Van Schmus, W.R., 1995. Natural radioactivity of the crust and mantle. In: Ahrens, T.J. (Ed.), Global Earth physics: A handbook of physical constants. AGU Reference Shelf 1, American Geophysical Union, Washington, D.C., pp. 283-291.

Wänke, H., Dreibus, G., 1988. Chemical composition and accretion history of terrestrial planets. Phil. Trans. R. Soc. London A 325, 545-557. 


\section{Figure Captions}

Figure 1. Relative radioactive heat production due to potassium, thorium and uranium (including ${ }^{238} \mathrm{U}$ and ${ }^{235} \mathrm{U}$ ) as a function of time. For comparative purposes, the point corresponding to four times the present-day value is shown for $2.6 \mathrm{Ga}$, since this value was used by Kargel and co-workers to represent the relative total heat production in that time.

Figure 2. Relative radioactive heat production due to bulk HPE abundances in Kargel and Lewis (1993), and Wänke and Dreibus (1988), as a function of time. The point corresponding to four times the present-day value for $2.6 \mathrm{Ga}$, as used by Kargel and coworkers is also shown.

Figure 3. Heat flow for Mars, as a function of time, equivalent to the total heat production due to HPE bulk abundances in Kargel and Lewis (1993) and Wänke and Dreibus (1988). Heat flows proposed by Kargel and co-workers for $2.6 \mathrm{Ga}$ and the presenttime are also shown (here labeled as $\mathrm{K} \& \mathrm{co}-\mathrm{W}$ ), as well as the corrected value (see Section 3) for $2.6 \mathrm{Ga}$. 


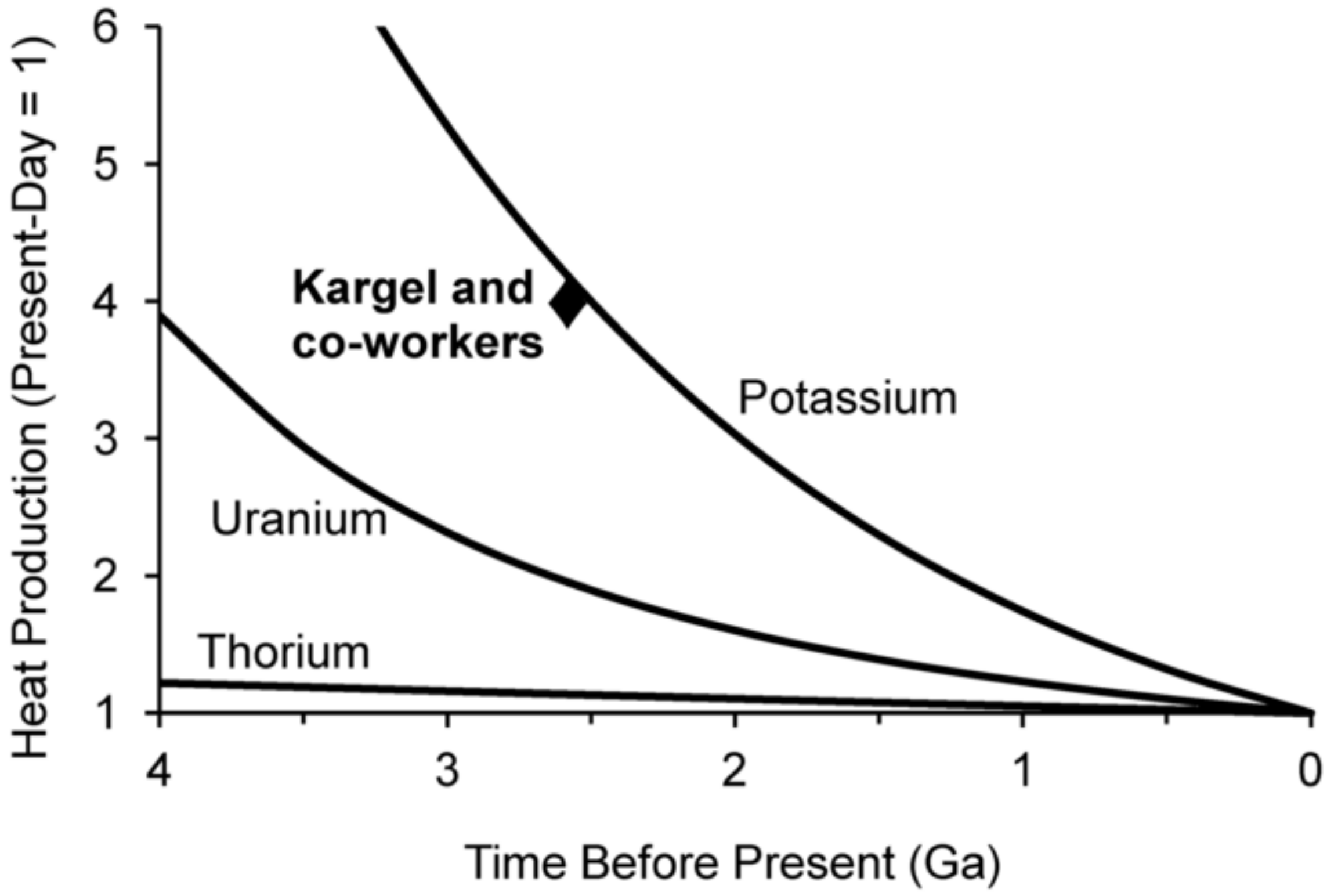




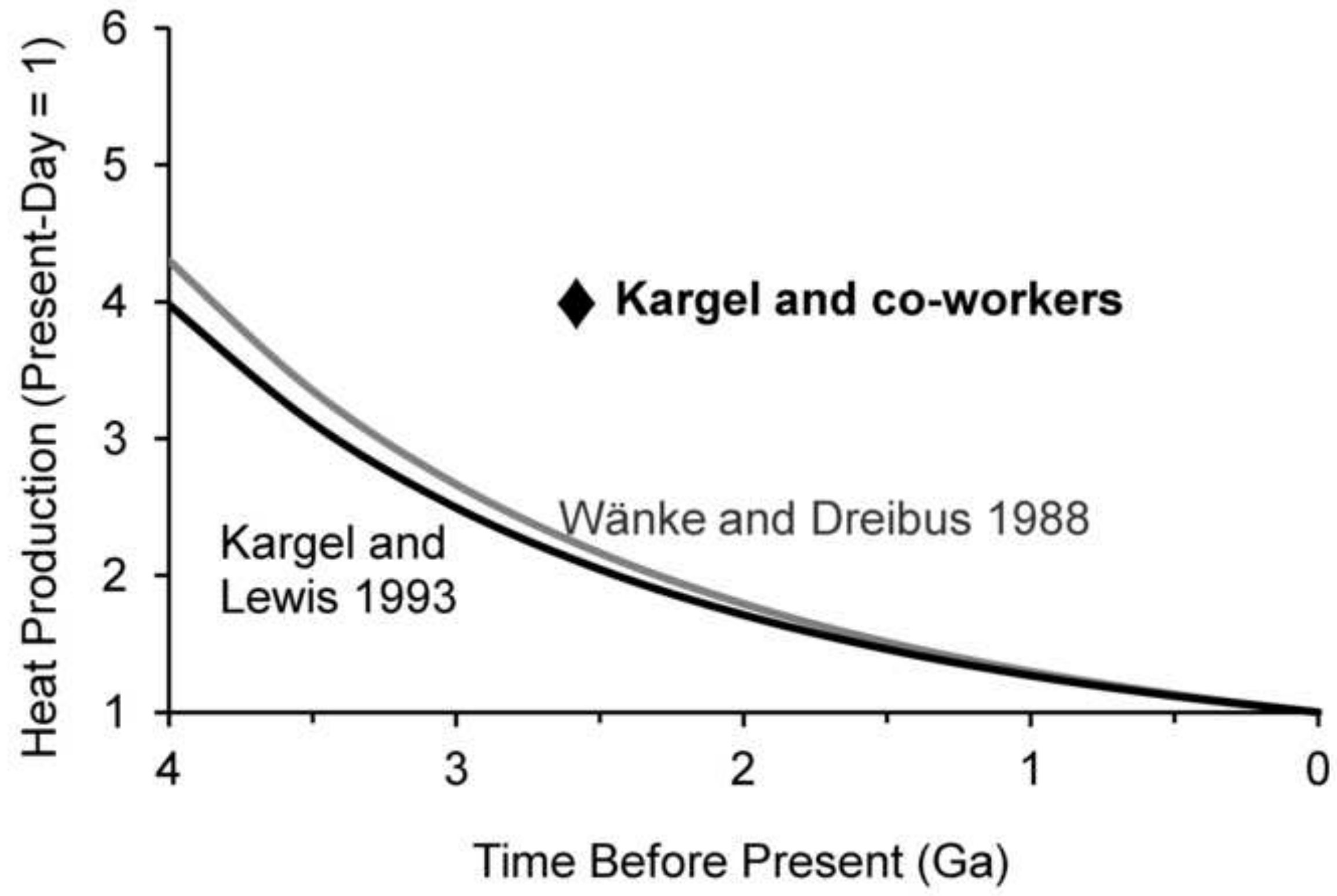




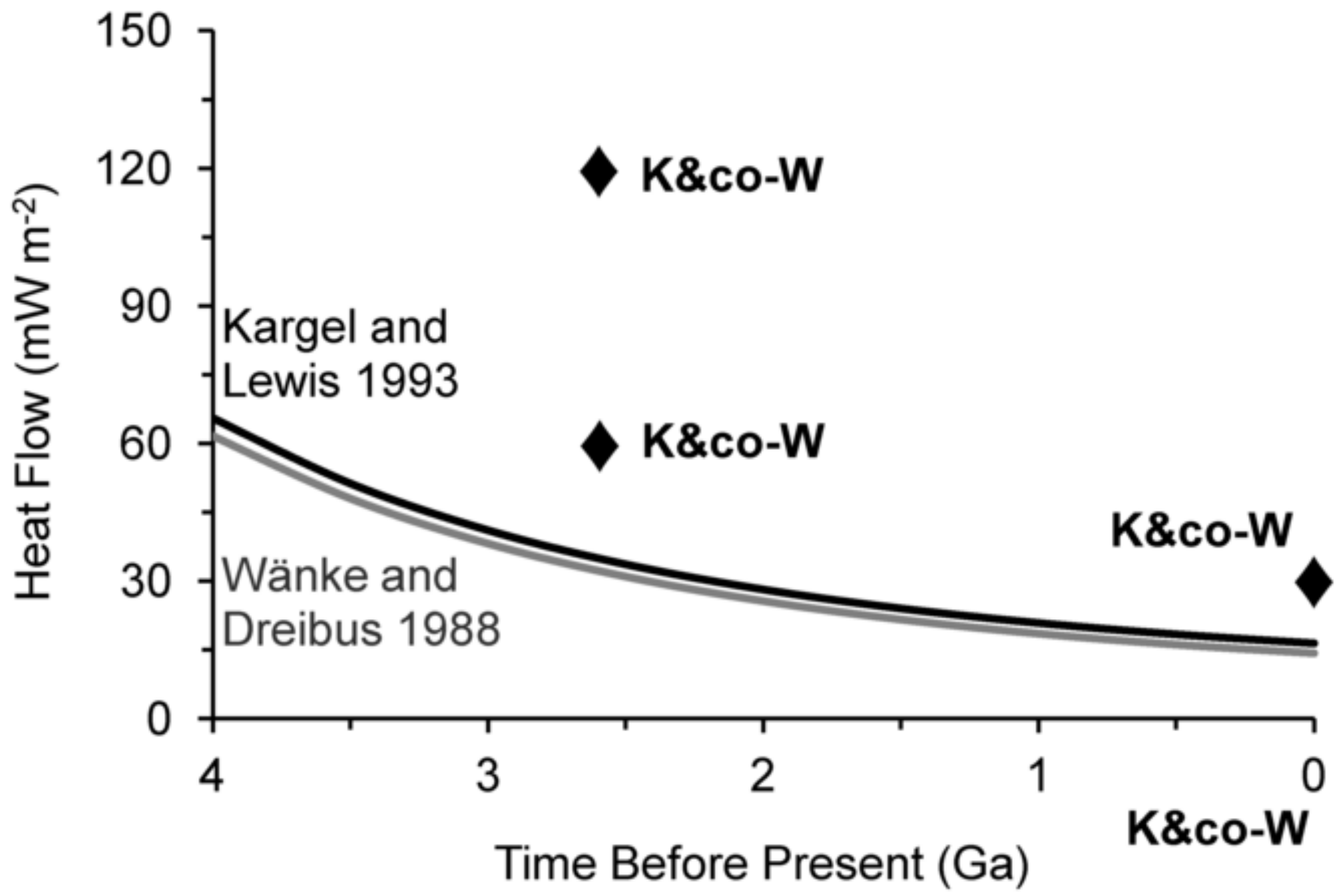

